\title{
Illicit drug use in the Flemish nightlife scene between 2003 and 2009
}

\section{Abstract}

Background/Aims

Given the importance of party people as innovators and early adaptors in the diffusion of substance use, and given the lack of longitudinal scope in studies of the nightlife scene, we explored changes in illicit drug use among young persons participating in nightlife in Flanders.

Methods

A survey among party people selected at dance events, rock festivals and in clubs was held in the summer of 2003 and repeated in 2005, 2007 and 2009. In total, 2812 respondents filled in a questionnaire on the use of cannabis, ecstasy, cocaine, amphetamines, GHB and ketamine.

Results

The results of the multiple logistic regression analyses show that in the group of frequent pub visitors, the predicting probability of cannabis use increased over time, while the gap in drug use between dance music lovers and non-lovers of dance music narrowed. For cocaine use during the last year, an increase was found related to the housing situation (alone or with parents) of respondents. While the odds of using ecstasy decreased over the years, the odds of using GHB increased.

Conclusion

We can conclude that monitoring emerging trends, which can be quickly observed in the nightlife scene, provides meaningful information for anticipating possible trends.

Keywords: nightlife, cannabis, ecstasy, cocaine, amphetamine, GHB, ketamine, prevention 
Introduction

Patterns of drug use are dynamic [1], or, as McCambridge et al. [2] phrased it: "Drug fashions come and go". A wide range of repeated epidemiological studies on trends in drug use have been published. In Europe, cannabis use seems to have stabilized in some countries (UK and France, for example), but increased in a few others countries (Italy and Slovakia, for example) [3]. Some experts have stated that ecstasy and amphetamine use has reached a plateau phase, with use of the latter substance possibly even decreasing [4-7]. When looking at cocaine, different patterns appear in Europe: in some countries with a high prevalence of cocaine use, the increase in use was followed by a stabilisation; in other countries, the prevalence of cocaine use more than doubled but remained relatively low [3]. More recently, the use of GHB and ketamine has been reported by dance drug users $[8,9]$. There have been reports from the UK and Australia on an increase in the use and availability of ketamine $[2,8,10,11]$.

However, most of these studies focused on the general population and might have underestimated the prevalence of drug use because of the under-sampling of hidden populations. To be able to respond to changes in drug patterns in a timely way, research should focus on innovators and early adopters [12] who can be found in specific settings, such as the nightlife scene. Several authors have stated that music festival goers [13] and dance scene attendees [2, 14] are interesting groups for identifying emerging drug trends. Tossmann and colleagues [15] investigated the use of psychotropic substances in seven metropolitan cities in Europe (Rome, Berlin,...) among techno party visitors. IREFREA, a leading research network on nightlife in nine European cities (Nice, Palma, Athens,...), has conducted several studies on recreational drug use in nightlife settings. These studies have mapped the use of illegal drugs such as cannabis, ecstasy, amphetamines and cocaine in the nightlife scene and concluded that illicit drug use is relatively widespread. Furthermore, poly drug use is the rule rather than the exception among young substance users during the weekend [16, 17]. Alcohol and cannabis are the most important substances in patterns of poly substance use, followed by ecstasy, amphetamines and cocaine [16]. [16][16]These studies are unique for their multi-city approach, but longitudinal studies in nightlife research are rare. To our knowledge, only four studies with a longitudinal scope have been published. In Melbourne, Lim and colleagues [13] concluded that illicit drug use was much more common among music festival attendees than among the general population, but the direction of trends in drug use was similar. McCambridge and colleagues [14] observed a reduction in the prevalence of ecstasy use, a stabilisation of cocaine use, and a fluctuation of amphetamine use between falling and rising in the UK. An increase in the lifetime prevalence of GHB and ketamine use was also found [2]. In 1993, the Bonger Institute launched the Antenna Monitor, which maps illicit drug use among young people in various nightlife settings in Amsterdam. The most recent Antenna Monitor (2010) concluded that cocaine remains popular in certain subgroups, and an increase in the use of ecstasy (after a decline) and amphetamines is observed. The use of GHB in Amsterdam is limited [18]. Demetrovics and his colleagues [19] carried out three surveys in Budapest in 1998, 1999 and 2003. Although the methodology differentiated over time, it could be concluded that the extent of recreational drug use in Hungarian clubs had increased. Although cannabis is the most widespread drug in Hungarian society, psycho-stimulants tended to be the drug of choice in nightlife settings. Moreover, respondents almost exclusively associated the use of such drugs with dance-music entertainment settings.

Given the lack of longitudinal scope in nightlife research, and given the importance of party people as innovators and early adaptors in the diffusion of substance use, we explored changes in illicit drug use among young people who participate in different nightlife settings in Flanders (the northern region of Belgium) through a bi-annual survey over the years 2003, 2005, 2007 and 2009. By using the same questionnaire and methodology every two years, we were able to look at the effects of time on illicit drug use. It is important to monitor trends to set up appropriate interventions, regardless whether one thinks of prevention, treatment or law enforcement [20]. This articles focuses on the most common illegal drugs in the nightlife scene in Flanders: cannabis, ecstasy, cocaine, amphetamines, GHB and ketamine. 
Materials and methods

Sample

This survey was administered in the Flemish nightlife scene between 2003 and 2009, using a self-report questionnaire. Each second year, a sample of party people was selected at three clubs, two dance events and two rock festivals in Flanders. These specific events and clubs were chosen because of their scale (to ensure a large enough sample size) and location (regional spread). The most popular clubs and events in Flanders were included in the study. The same locations were involved each year of the survey, with the exception of events that were organized only once. In this case, a comparable event was included with similar characteristics such as music styles, visitor profiles, number of attendees and indoor/outdoor event.

At each event, poll-takers asked visitors to participate in this survey over two times a period of one hour. Interviewers selected a spot in the club or at the event where there was enough light and space to fill in the questionnaire (e.g. near toilets in clubs). In order to avoid selection bias, the poll-takers invited every fifth visitor who came by to complete a short questionnaire. They made sure that the questionnaire could be filled in discreetly by ensuring a private space near the interviewer. Informed consent for study participation was asked in the introduction of the questionnaire. Non-Belgian residents (due to the different legal framework concerning cannabis in neighbouring countries like the Netherlands), persons who volunteered to participate in the study and those who had already taken part in the survey that summer were excluded. The chance of recruiting the same attendees at multiple events was very small. According to the poll-takers, visitors who had already been asked to fill out the questionnaire that summer usually reported this. Because the questionnaire was in Dutch, only Dutch-speaking Belgians could participate. Each survey year from 2003 until 2009, between 645 and 775 respondents filled in the questionnaires, with a total of 2812 respondents. Overall, the response rate was $62.9 \%$. In $200364.3 \%$ of the selected individuals filled in a questionnaire, in $200557.7 \%$ did so, in 2007 it was $66.2 \%$ and in $65.4 \%$ it was 2009. No information on gender or other characteristics of nonrespondents could be collected. In this survey, we make no claim that the data from any particular year are representative of the wider population.

\section{Procedure}

The survey was first administered in July of 2003 and was repeated every two years between July and October. Data were gathered during four survey years: 2003, 2005, 2007 and 2009. Club owners and event organizers gave their permission to recruit participants at the venues. Agreements were made concerning the anonymous reporting of clubs and events. To guarantee anonymity, the respondents were asked to complete the questionnaire on their own, even in cases where they wanted the researchers to help them. The questionnaire was limited to five pages to encourage participation. Filling in the questionnaire took the respondents an average of 10 minutes. No payment or reward was given to the study participants.

All interviewers involved in the data collection were trained prior to the study. Two poll-takers approached visitors in clubs between 1 a.m. and 4 a.m. Before 1 a.m., not enough visitors attended the clubs, whereas after 4 a.m. too many visitors were under the influence of psychoactive substances. At rock festivals, the data were collected by three interviewers between 3 p.m. and 8 p.m., while at dance events this happened between 9 p.m. and 12 p.m. 
The questionnaire primarily consisted of multiple-choice questions; it also included two open-ended questions. The first section of the questionnaire included relevant demographic information (age, gender, profession, living status, sexual identity) [16]. The second section focused on patterns of going out (favourite music, setting, frequency) [21]. Eighteen music styles were listed in the questionnaire and the respondents cited their favourite music style(s) (no limitation was imposed on possible answers). Categories for music preferences were based on an Internet search of relevant websites and were approved during an expert meeting of prevention workers and nightlife professionals. Another question referred to the nightlife settings that had been visited during the last 30 days (e.g. pubs, clubs, goa parties). The third part assessed the (frequency of) substance use $[15,21]$. Seven categories for the frequency of drug use were distinguished: 1) never used this drug; 2) have used, but not in the last year; 3) once a month or less; 4) several times a month; 5) once a week; 6 ) several times a week; and 7) daily. The fourth section was intended only for people who had used illegal substances within the last year and consisted of questions on the context of substance use: when and with whom they used (patterns of use), and where and when they bought their drugs [22]. The fifth part focused on combined substance use (frequency and substances) [22]. Each respondent was also asked to complete the sixth section on preventive health measures regarding substance use [23]. The last section of the questionnaire consisted of open-ended questions on emerging trends in (patterns of) drug use.

\section{Data analysis}

To test the reliability of the respondents' answers, an imaginary substance (NTSC) was added to the list of substances. Respondents who reported NTSC use were excluded from the analyses, as their answers were deemed not reliable (= overall 4.01\%). Ultimately, this article reports on findings among the remaining 2697 respondents recruited in 2003, 2005, 2007 and 2009 (Table 1). For investigating differences concerning survey years and demographic variables, we used chi-square tests for non-continuous variables (profession, living status and gender) and ANOVA for assessing age differences.

To examine trends in substance use, six separate models were built using multiple logistic regressions. In each of these models, the last-year (yes/no) use of cannabis, ecstasy, cocaine, amphetamine, GHB or ketamine served as dependent variables. The following independent variables were entered into the model in a stepwise way (both forward and backward): last month frequency of going to pubs, clubs, concerts, festivals, youth clubs and mainstream parties; profession; living status; and preference for rock music, dance music and southern music. We chose to enter survey year, gender and age as fixed factors in each of the models because they were central to the purposes of this study.

Initially, all models were built allowing second-order interactions between all variables. However, for GHB, amphetamines and ketamine, this was not possible because of the lack of data in certain cell combinations. Therefore, the stepwise selection procedure for these three substances was narrowed to the main effects only. Since we were mainly interested in trends over the years, the focus of the results was on the variable year and its interactions. Consequently, we limited the table of the multiple logistic regression analyses to the variable survey year and its interactions, although the analyses revealed more results than are discussed in the results section (Table 2).

All analyses were performed using the statistical software program R, version 2.12 [24]. To ease the interpretation of higher-order effects, we also produced one figure of predicted probabilities using the "effects" package [25]. In this package, the predicted probabilities are computed for some "interesting" values of the other predictors. In fact, for the continuous predictors the mean is used, whereas for categorical predictors the observed proportions are used. The goodness of fit of the logistic regression models was verified using the Hosmer-Lemeshow test [26]. The level of statistical significance was set at $\alpha=0.05$. 
No significant differences were found between the survey years $(2003,2005,2007,2009)$ in terms of age $(F(3$, $2462)=2.23, p=0.083)$, profession $\left(\chi^{2}(3)=3.17, p=0.366\right)$ or living status $\left(\chi^{2}(3)=1.59, p=0.661\right)($ Table 1$)$. A difference was found regarding gender across the four samples $\left(\chi^{2}(3)=21.60, p<.001\right)$ : looking at the gender proportions, it appeared that increasing numbers of women participated in the survey on drugs and nightlife over the years (Table 1). Consequently, we can conclude that, with the exception of gender, the groups of respondents were comparable over the years regarding these demographic variables.

Across the four survey years, the most commonly used illegal drug was cannabis (43.1\%). Its prevalence has always been much higher than for other substances, including popular party drugs like ecstasy (16.1\%), cocaine (13.4\%) and amphetamines (8.2\%). In the last survey year (2009), it was noted that cocaine had switched places with ecstasy to become the second most commonly used drug. Of all drugs, GHB(3.0\%) and ketamine (1.9\%) were the least commonly used drugs in the nightlife scene (Figure 1).

\section{Effects of time}

\section{Cannabis}

No significant main effect of survey year was found on the use of cannabis in the last year, but there were some clear trends in its interactions. First, an interaction was found between pub attendance frequency and survey year (LRT $\left.\chi^{2}(3): 15.82, p<0.01\right)$. Over the years, the relation between pub attendance frequency and cannabis use became stronger and more positive (Figure 2). Second, an interaction effect was observed between festival attendance frequency and survey year (LRT $\left.\chi^{2}(3): 8.15, p=0.04\right)$. However, there was no clear interpretable pattern in this fluctuation (Table 2). Third, an interaction between self-reported dance music preference and survey year was also found (LRT $\chi^{2}(3): 11.63, p<0.01$ ). Overall, the odds of having used cannabis during the last year were 2.97 times higher for dance music lovers compared to non-dance music lovers $(95 \% \mathrm{Cl}:[1.73,5.21], \mathrm{p}<0.01)$. However, the interaction with survey year means that in terms of the predicted probability of cannabis use in the last year, the difference between votaries and non-votaries of dance music decreased over the years.

\section{Ecstasy}

A significant association was observed between survey year and the use of ecstasy (LRT $\chi^{2}(3): 9.92, p=0.02$ ): on average, the odds of having used ecstasy in the last year compared to 2003 decreased over the years, especially in 2005 and 2009 (Table 2).

\section{Cocaine}

No significant main effect of survey year was found on the use of cocaine in the last year, but an interaction was found between survey year and housing situation (LRT $\left.\chi^{2}(3): 4.49, p=0.03\right)$. For the respondents who lived independently (with a partner or alone), as well as for those who lived with their parents, a sudden increase was observed in the predicted probability of cocaine use in the last year in comparison to 2003. However, this sudden increase occurred two years earlier for the respondents who lived independently (2007) compared to the respondents who lived with their parents (2009) (Table 2).

\section{Amphetamines, GHB and ketamine}

For reasons mentioned previously, the stepwise selection procedure for GHB, ketamine and amphetamines was narrowed to main effects only (Table 2). The results of amphetamine and ketamine use in the last year showed no significant evolution over the years (LRT $\chi^{2}(3): 2.76, p=0.43$ and LRT $\chi^{2}(3): 5.14, p=0.16$, 
respectively). For GHB, the results indicate that, while the odds of having used GHB in the last year were low, on average they increased over the years in comparison to 2003 (LRT $\left.\chi^{2}(3): 11.17, p=0.01\right)$.

\section{Discussion}

Although clubbers and visitors of music festivals and events are often difficult to reach for research, we were able to recruit nearly 3000 respondents at festivals, dance events and clubs. Belgium offers an excellent opportunity for focusing on several different nightlife scenes, since it is known for its variety of music styles and venues and it has several large music events. Based on our analysis of the evolution of illicit drug use over a seven-year period (2003-2009) in Flanders (Belgium), we can conclude that the use of most illegal substances are changing over time. Consequently, health promotion and drug prevention initiatives need to proactively anticipate shifts in drug use [1].

Before discussing the most important results, it is necessary to look at the limitations of this study. Second, this study was not representative of party people in Belgium. A more appropriate method for studying party people would be to conduct a survey during an entire year at various venues. In addition, the use of online surveys would allow researchers to reach more respondents, although this could raise other methodological issues, such as the problem of double counting or questions about the representativeness of the study sample. Furthermore, an online survey might attract people interested in drug use and induce sampling bias. Our experience with face-to-face selection showed that people who did not want to participate at first changed their minds when given more information. Several authors have shown that, even in party environments, questionnaires can be used as reliable tools for assessment [27, 28]. Though poll-takers could not guarantee that the respondents were not under the influence of a substance when they filled out the survey, making informed consent disputable, individuals who showed clearly observable symptoms of intoxication were excluded from the study.

In this study of the nightlife scene in Flanders, we were able to keep the sampling procedure, locations and questionnaire (almost) identical over the survey years, enabling us to look at the effect of time on illicit drug use. Ecstasy was the only drug in this study that showed a decreasing trend in use, as confirmed by international data [7]. Measham [5] argued that ecstasy pills were undergoing a shift from their subcultural iconic status as the "cultural signifier of a generation" to a cheeky supplement to a night's drinking. This does not mean per se that the quantity of ecstasy consumed by users also diminished. Although McCambridge et al. [14] confirmed the trend of reduced use of ecstasy, they also found evidence of patterns of higher consumption (number of pills) among current users. Prevention projects should especially target ecstasy users who use excessively and/or are taking these pills in combination with other drugs, thus displaying specific risk behaviour.

The odds of using cocaine increased with each survey year, which could indicate that it is becoming more widespread. Golub and colleagues [29] call this the expansion phase: pioneering drug users successfully introduce the practice to wider groups of users and to the broader population. This could be due to the increase in availability and the decrease in the price of cocaine, making the drug more easily attainable [1,30]. Regarding last-year substance use, it seems that cocaine switched places with ecstasy. Prevention initiatives should focus on those who are not (yet) using these drugs, but their widespread use also confirms the need for harm reduction projects in the nightlife scene, for example, peer support projects or information campaigns on possible risks (e.g. risks of combining alcohol and cocaine) for party people who are already using these substances.

Last-year cannabis use showed an increase over the years in the group of non-dance music lovers and in the group of respondents who visited pubs more frequently. The odds of cannabis use last year for non-dance music lovers almost reached the level of the dance music lovers. According to Golub's phases, these are 
characteristics of the plateau phase [29] or, as Nabben [31] calls it, "use by the mainstream group", in which everyone at risk of using the new drug practice has either initiated its use or at least had the opportunity to try it. Music festivals may be important arenas for trying to prevent the onset of cannabis use [32].

An increase in the use of GHB was detected over the four survey years. Although the last-year use of this drug was still marginal, in the most recent survey (3.1\%) the frequency of use (almost) doubled in comparison with the first survey year. Also, in the UK, the use of GHB increased in a sample of dance drug users over a five-year period [2]. According to the phases of Golub and colleagues [29], it seems that GHB is in the incubation phase, in which a limited subpopulation, like the dance club scene, uses this substance. Its use seems to be limited to a group of trend setters, and its increased use could include trend followers as well [31]. The question is whether the use of GHB will become more widespread. The use of GHB should be closely monitored [18] given its potential for overdose and other harmful consequences [2]. GHB overdose has been reported more frequently than for any other dance drug, especially when combined with alcohol [33]. Prevention messages should include information on the use of GHB, especially in combination with alcohol, as this combination may induce depressed breathing and unconsciousness.

Since the late eighties, cocaine and ecstasy have slowly pushed amphetamines into the background of the nightlife scene. However, the use of amphetamines in the nightlife scene did not change over the years in the present study. This was confirmed in a recent report of the EMCDDA [7], which supports these data. Some subgroups in the party scene are attracted to this drug [31] and, according to Measham [5], we should not be surprised if a reduction in one form of psychoactive consumption is accompanied by an upsurge in another. Other new drugs such as mephedrone, which could be legally obtained until April 2010 and is cheap, should be watched closely. A panel study on new trends in drug use in Amsterdam (Antenna) concluded that mephedrone will not be able to replace the effects of ecstasy [18]. New drugs with aversive effects (e.g. ketamine) are unlikely to be used widely [34].

Subcultures, particularly drug subcultures, undergo continuous change, not just in terms of the shifting prevalence of substance use over time but also in venues, symbolic meanings, conduct norms and behavioural patterns [29]. Due to new technologies (e.g. the Internet) and social evolutions (for example, young people on holiday in typical nightlife resorts such as Ibiza are sometimes recruited into using substances they have not used before [35]), drug fashions could change more rapidly than every two years. A bi-annual survey may fall behind when it comes to anticipating new trends, and therefore this survey was complemented with qualitative interviews with key stakeholders in the nightlife scene every second year. Sensitive tools for monitoring trends in drug use and insights are an essential part of understanding trends [20]. Finally, the conversion of variables to a statistical representation does not enable us to understand why these shifts in drug use are being seen, but the changes and evolutions seen in the prevalence of illicit drugs enable health promotion and drug prevention initiatives to anticipate possible trends and provide relevant information to possible user groups.

\section{Acknowledgements}

This study was designed and performed by the Flemish Association on Alcohol and Drug Problems (VAD, Vereniging voor Alcohol- en andere Drugproblemen). The VAD is the Belgian EMCDDA sub-focal point for Flanders. We would like to thank the poll-takers, in particular Jochen Schrooten, for their hard work. Furthermore, we are grateful to the club owners, promoters and organizers for their cooperation with this study. Without the respondents giving us ten minutes of their time, this study would not have been possible, so we thank them as well. 


\section{References}

1. Riley SCE, Hayward E: Patterns, trends, and meanings of drug use by dance-drug users in Edinburgh, Scotland. Drugs-Education Prevention and Policy 2004; 11:243-262.

2. McCambridge J, Winstock A, Hunt N, Mitcheson L: 5-year trends in use of hallucinogens and other adjunct drugs among UK dance drug users. European Addiction Research 2007; 13:57-64.

3. EMCDDA: 2010 Annual report on the state of the drugs problem in Europe. Lisbon, EMCDDA, 2010.

4. OFDT: Tendances nr. 7: Recent trends relating to psychoactive substances use and synthetic substances components. OFDT, 2000.

5. Measham F: The decline of ecstasy, the rise of 'binge' drinking and the persistence of pleasure. The Journal of Community and Criminal Justice 2004; 51:309-326.

6. Maxwell JC: Patterns of Club Drug Use in the U.S. Austin, TX, Gulf Coast Addiction Technology Center, 2004.

7. EMCDDA: 2009 Annual report on the state of the drugs problem in Europe. Lisbon, EMCDDA, 2009.

8. Degenhardt L, Copeland J, Dillon P: Recent trends in the use of "club drugs": An Australian review. Substance Use and Misuse 2005; 40:1241-1256.

9. Ramo DE, Grov C, Delucchi L, Kelly BC, Parsons JT: Typology of club drug use among young adults recruited using time-space sampling. Drug and Alcohol Dependence 2010; 107:119-127.

10. Curran HV, Monaghan L: In and out of the K-hole: a comparison of the acute and residual effects of ketamine in frequent and infrequent ketamine users. Addiction 2001; 96:749-760.

11. Degenhardt L, Dunn M: The epidemiology of GHB and ketamine use in an Australian household survey. International Journal of Drug Policy 2008; 19:311-316.

12. Rogers EM: Diffusion of Innovations. New York, Free Press, 2003.

13. Lim MSC, Hellard ME, Hocking JS, Spelman TD, Aitken CK: Surveillance of drug use among young people attending a music festival in Australia, 2005-2008. Drug and Alcohol Review 2010; 29:150-156.

14. McCambridge J, Mitcheson L, Winstock A, Hunt N: Five-year trends in patterns of drug use among people who use stimulants in dance contexts in the United Kingdom. Addiction 2005; 100:1140-1149.

15. Tossmann P, Boldt S, Tensil MD: The use of drugs within the techno party scene in European metropolitan cities. European Addiction Research 2001; 7:2-23.

16. Calafat A, Bohrn K, Juan M, Kokkevi A, Maalsté N, Mendes F, Palmer A, Sherlock K, Simon J, Stocco P, Sureda MP, Tossmann P, Wijngaart Gvd, Zavatti P: Nightlife in Europe and recreative drug use. Sonar 98. Valencia, Irefrea, 1999.

17. Calafat A, Fernández $C$, Juan $M$, Bellis $M$, Bohrn K, Hakkarainen $P$, Kilfoyle-Carrington $M$, Kokkevi $A$, Maalsté N, Mendes F, Siamou I, Simon J, Stocco P, Zavatti P: Risk and control in the recreational drug culture - SONAR project. Palma De Mallorca, Irefrea, 2001.

18. Benschop A, Nabben T, Korf DJ: Antenne 2010: Trends in alcohol, tabak en drugs bij jonge Amsterdammers. Amsterdam, Rozenberg Publishers, 2011.

19. Demetrovics Z: Hungary. In Nightlife and crime: social order and governance in international perspective. Edited by Hadfield P. Oxford: Oxford University Press; 2009

20. Agar $\mathrm{MH}$ : Towards a trend theory. In Understanding and responding to drug use: the role of qualitative research. Edited by Greenwood G, Robertson K. Lissabon: EMCDDA; 2000:67-72. 
21. Winstock AR, Griffiths P, Stewart D: Drugs and the dance music scene: a survey of current drug use patterns among a sample of dance music enthusiasts in the UK. Drug and Alcohol Dependence 2001; 64:9-17.

22. Riley SCE, James C, Gregory D, Dingle H, Cadger M: Patterns of recreational drug use at dance events in Edinburgh, Scotland. Addiction 2001; 96:1035-1047.

23. Hacourt G: Ecstasy: pilules sans ordonnances: usages et usagers de nouvelles drogues de synthèse. Paris, L'Harmattan, 2002.

24. R Development Core Team: R: A language and environment for statistical computing. Vienna, 2010.

25. Fox J: Effect Displays in R for Generalised Linear Models. Journal of Statistical Software 2003; 8:1-27.

26. Hosmer DW, Lemeshow S: Applied Logistic Regression. New York, Wiley, 2000.

27. van de Wijngaart G, Braam R, de Bruin D, Fris M, Maalste NJM, Verbraeck HT: Ecstasy use at largescale dance events in the Netherlands. Journal of Drug Issues 1999; 29:679-701.

28. Ter Bogt TFM, Engels R: "Partying" hard: Party style, motives for and effects of MDMA use at rave parties. Substance Use and Misuse 2005; 40:1479-1502.

29. Golub A, Johnson BD, Dunlap E: Subcultural evolution and illicit drug use. Addiction Research \& Theory 2005; 13:217-229.

30. Decorte T, Slock M: The taming of cocaine II: a 6-year follow up study of 77 cocaine and crack users. Brussel, VUB University Press, 2005.

31. Nabben T: High Amsterdam: ritme, roes en regels in het uitgaansleven (High Amsterdam: rythm, rush and rules in nightlife). Amsterdam, Rozenberg Publishers, 2010.

32. Hesse $M$, Tutenges $S$, Schliewe S: The use of tobacco and cannabis at an international music festival. European Addiction Research 2010; 16:208-212.

33. Kim SY, Anderson IB, Dyer JE, Barker JC, Blanc PD: High-risk behaviors and hospitalizations among gamma hydroxybutyrate (GHB) users. American Journal of Drug and Alcohol Abuse 2007; 33:429-438.

34. EMCDDA: Report on the risk assessment of ketamine in the framework of the joint action on new synthetic drugs. Luxembourg, Office for the Official Publications of the European Communities, 2002.

35. Bellis MA, Hughes $K$, Bennett A, Thomson R: The role of an international nightlife resort in the proliferation of recreational drugs. Addiction 2003; 98:1713-1721. 
Table 1: Demographic variables over the survey years

\begin{tabular}{|c|c|c|c|c|c|}
\hline & & 2003 & 2005 & 2007 & 2009 \\
\hline $\mathbf{N}$ & & 645 & 670 & 775 & 607 \\
\hline $\operatorname{Age}^{x}$ & & $22.03(S D=5.26)$ & $22.66(S D=5.41)$ & $22.69(S D=5.86)$ & $22.17(S D=5.84)$ \\
\hline \multicolumn{6}{|c|}{ Profession ${ }^{x}$} \\
\hline & Student & $51.2 \%$ & $48.2 \%$ & $46.4 \%$ & $49.3 \%$ \\
\hline & Working & $48.8 \%$ & $51.8 \%$ & $53.6 \%$ & $50.7 \%$ \\
\hline \multicolumn{6}{|c|}{ Living status ${ }^{\mathrm{x}}$} \\
\hline & With parents & $33.3 \%$ & $36.6 \%$ & $35.0 \%$ & $35.3 \%$ \\
\hline & Individually & $66.7 \%$ & $63.4 \%$ & $65.0 \%$ & $64.7 \%$ \\
\hline \multicolumn{6}{|c|}{ Gender * } \\
\hline & Male & $64.5 \%$ & $67.8 \%$ & $61.8 \%$ & $55.5 \%$ \\
\hline & Female & $35.5 \%$ & $32.2 \%$ & $38.2 \%$ & $44.5 \%$ \\
\hline
\end{tabular}

not significant

* $\chi^{2}(3)=21.60, p<.001$ 
Table 2: Predictors of last year substance use

\begin{tabular}{|c|c|c|c|c|}
\hline & & AOR & $95 \% \mathrm{Cl}$ & $p$-value \\
\hline \multirow[t]{25}{*}{ Cannabis } & Survey year & & & \\
\hline & 2003 (ref) & 1.0 & & \\
\hline & 2005 & 1.21 & $0.63,2.31$ & 0.560 \\
\hline & 2007 & 1.78 & $0.92,3.46$ & 0.085 \\
\hline & 2009 & 1.86 & $0.96,3.61$ & 0.066 \\
\hline & $\begin{array}{l}\text { Interaction between going to the pub } \\
\text { and survey year }\end{array}$ & & & \\
\hline & Pub $\times 2003$ (ref) & 1.0 & & \\
\hline & Pub $\times 2005$ & 1.04 & $0.99,1.08$ & 0.095 \\
\hline & Pub $\times 2007$ & 1.05 & $1.01,1.10$ & 0.010 \\
\hline & Pub × 2009 & 1.09 & $1.04,1.14$ & $<0.001$ \\
\hline & $\begin{array}{l}\text { Interaction between liking dance music } \\
\text { and survey year }\end{array}$ & & & \\
\hline & Dance music $\times 2003$ (ref) & 1.0 & & \\
\hline & Dance music $\times 2005$ & 0.36 & $0.18,0.72$ & 0.004 \\
\hline & Dance music $\times 2007$ & 0.44 & $0.21,0.89$ & 0.023 \\
\hline & Dance music × 2009 & 0.35 & $0.17,0.72$ & 0.004 \\
\hline & $\begin{array}{l}\text { Interaction between going to clubs and } \\
\text { survey year }\end{array}$ & & & \\
\hline & Clubs $\times 2003$ (ref) & 1.0 & & \\
\hline & Clubs $\times 2005$ & 0.87 & $0.77,0.98$ & 0.019 \\
\hline & Clubs $\times 2007$ & 0.87 & $0.78,0.97$ & 0.014 \\
\hline & Clubs $\times 2009$ & 0.92 & $0.80,1.05$ & 0.213 \\
\hline & $\begin{array}{l}\text { Interaction between going to festivals } \\
\text { and survey year }\end{array}$ & & & \\
\hline & Festivals $\times 2003$ (ref) & 1.0 & & \\
\hline & Festivals $\times 2005$ & 0.87 & $0.71,1.06$ & 0.178 \\
\hline & Festivals × 2007 & 1.18 & $0.96,1.46$ & 0.135 \\
\hline & Festivals $\times 2009$ & 0.96 & $0.75,1.21$ & 0.715 \\
\hline \multirow[t]{10}{*}{ Ecstasy } & Survey year & & & \\
\hline & 2003 (ref) & 1.00 & & \\
\hline & 2005 & 0.65 & $0.45,0.93$ & 0.020 \\
\hline & 2007 & 0.71 & $0.50,1.01$ & 0.054 \\
\hline & 2009 & 0.54 & $0.35,0.81$ & 0.003 \\
\hline & $\begin{array}{l}\text { Interaction between going to the pub } \\
\text { and survey year }\end{array}$ & & & \\
\hline & Pub $\times 2003$ (ref) & 1.00 & & \\
\hline & Pub $\times 2005$ & 0.95 & $0.90,1.00$ & 0.061 \\
\hline & Pub $\times 2007$ & 1.02 & $0.98,1.07$ & 0.366 \\
\hline & Pub × 2009 & 1.02 & $0.96,1.08$ & 0.526 \\
\hline \multirow[t]{8}{*}{ Cocaine } & Survey year & & & \\
\hline & 2003 (ref) & 1.00 & & \\
\hline & 2005 & 0.93 & $0.51,1.70$ & 0.800 \\
\hline & 2007 & 0.77 & $0.43,1.41$ & 0.400 \\
\hline & 2009 & 1.64 & $0.90,3.03$ & 0.109 \\
\hline & $\begin{array}{l}\text { Interaction between living status and } \\
\text { survey year }\end{array}$ & & & \\
\hline & Living on their own × 2003 (ref) & 1.00 & & \\
\hline & Living on their own $\times 2005$ & 1.09 & $0.46,2.56$ & 0.847 \\
\hline
\end{tabular}




\begin{tabular}{lllll} 
& Living on their own $\times 2007$ & 2.51 & $1.13,5.63$ & 0.024 \\
& Living on their own $\times 2009$ & 0.86 & $0.36,2.03$ & 0.727 \\
\hline Amphetamines & Survey year & & & \\
& 2003 (ref) & 1.00 & & \\
& 2005 & 0.68 & $0.42,1.09$ & 0.108 \\
& 2007 & 0.84 & $0.55,1.31$ & 0.444 \\
& 2009 & 0.77 & $0.46,1.27$ & 0.306 \\
\hline GHB & Survey year & & & \\
& 2003 (ref) & 1.00 & & \\
& 2005 & 0.49 & $0.15,1.45$ & 0.212 \\
& 2007 & 1.82 & $0.84,4.27$ & 0.143 \\
& 2009 & 2.05 & $0.86,5.11$ & 0.110 \\
\hline Ketamine & Survey year & & & \\
& 2003 (ref) & 1.00 & & \\
& 2005 & 2.01 & $0.52,9.72$ & 0.330 \\
& 2007 & 2.66 & $0.78,12.13$ & 0.148 \\
& 2009 & 4.24 & $1.17,20.12$ & 0.040 \\
\hline
\end{tabular}


Figure 1: Last year drug use by and over survey years 
Figure 2: Evolution in the use of cannabis over time and frequency of pub attendance 